\title{
A Study on Health Monitoring of Structural Damages for Two Stories Model by Using Vibration Test
}

\author{
Toshikazu Ikemoto, Reza Amiraslanzadeh, Masakatsu Miyajima \\ School of Environmental Design, College of Science and Engineering, Kanazawa University, Kanazawa, Japan \\ Email: tikemoto@t.kanazawa-u.ac.jp, r.amiraslanzadeh@stu.kanazawa-u.ac.jp, miyajima@se.kanazawa-u.ac.jp
}

Received 26 September 2014; revised 20 October 2014; accepted 18 November 2014

Copyright (C) 2014 by authors and Scientific Research Publishing Inc.

This work is licensed under the Creative Commons Attribution International License (CC BY). http://creativecommons.org/licenses/by/4.0/

(c) (7) Open Access

\begin{abstract}
Many structures in Japan were built after the war at a revival term or rapid economic growth. These structures have been reached a life in recent years and it is economically not affordable to conduct repair and reconstruct these structures only with a possibility of being damaged. This paper presents an approach to detect the structural damages for two degrees of freedom (2DOF) model. In this study, we conducted Microtremor measurement, free vibration test and vibration test. The 2DOF model was demonstrated the feasibility of using the proposed approach to damage detection of structural member.
\end{abstract}

Keywords

Health Monitoring, Structural Damage, Vibration Test, Microtremor Measurements

\section{Introduction}

After a large earthquake, detection of damages in structures such as hospitals, bridges, and fire stations is very important. Therefore it is vital to conduct health monitoring to prevent secondary disaster. Numerous techniques have been presented in the literature on health monitoring of structures. Each researcher has applied different techniques to a different structure therefore it is difficult to compare merits, drawbacks and limitations of these various methodologies [1]-[4].

The ASCE task group recently developed structural health monitoring technique [5]. Structural health monitoring allows the engineer to use sensing of the structural responses in conjunctions with appropriate data analysis and modeling techniques to monitor the condition of a structure.

This paper presents an approach to detect structural damage for two degrees of freedom (2DOF) model. We 
conducted microtremor measurement, free vibration test and forced vibration test for health monitoring of the model. The forced vibration test simply consisted of a low amplitude vibration imposed by an electro-shaker that has been installed at the roof level.

The proposed method is a three-step approach. In the first step, we estimated change of the natural frequency of damaged structural models comparing with that of the undamaged one. The change of natural frequency could be assigned as one of the prevalent damage detection method in health structural assessment techniques. When a damage exists in a structure, the stiffness is reduced and as a result, the natural frequency starts decreasing. One of the most advantages of this detection technique is that frequency measurements can be quickly and easily conducted. Moreover, experimental techniques used for the determination of resonant frequencies are classical vibrational measurement techniques; thus allowing the vibrational measurements to be extensive with a great number of measurement points and a very cheap experimental procedure [6]-[10].

Any undamped system vibrating at one of its natural frequencies can be reduced to the simple problem of a mass $m$ attached to a spring of stiffness $k$ (Equation (1)). The lowest natural frequency of such a system is:

$$
f=\frac{1}{2 \pi} \sqrt{\frac{k}{m}}
$$

Specific cases require specific values for $m$ and $k$. They can often be estimated with sufficient curacy to be useful in approximate modeling. In the second step, dynamic properties of the floors were analyzed by using response acceleration records on each floor level. Observed data for floors were analyzed in the frequency domain. The ratio of Fourier spectrum has considered in order to study the characterization and change of amplification between two floors. The ratio of Fourier spectrum between the first floor level and the second one indicates the damaged floor. In the third step, the strain was measured at specified locations on column members. We defined the maximum strain ratio of the damaged member to the undamaged member. As defined below, the ratio of extension to original length is called strain it has no units as it is a ratio of two measured lengths (Equation (2)).

$$
\text { Strain }=\frac{\Delta L}{L}
$$

where $\Delta L$ is the measured extension in metric units and $L$ is original length measured in the same unit. This strain ratio was used to detect damaged member of the model structure.

\section{Description of the Model}

A 3D steel frame model with two stories and single span was designed and built. According to the old codes roof in Japan structures is made by light materials, and based on the said assumption the model was structured without roof, and only columns and beams were considered. The model was $2.4 \mathrm{~m}$ tall with a span width of 1.2 $\mathrm{m}$ and $1.2 \mathrm{~m}$ height for each story. Whole size of the model as well as sizes of the all profiles was in an approximate scale of 1:3. The connections were carried out through the blots without joints and the model assumed as a rigid-free-condition model. Each beam and column member restrained between two joints has the length of 1.2 $\mathrm{m}$ with I-shape cross section and height and width of 10 and $5 \mathrm{~cm}$, respectively.

\section{Configuration Cases}

The measurements were performed for twelve test configuration cases. All test configurations were conducted at the full amplitude forced vibration levels. Furthermore, $1 / 3$ amplitude was applied in the work, but the obtained strain was not satisfactory for the considered $1 / 3$ scale and 1/3 amplitude, thus we believe that full amplitude forced vibration could give us more clear results, thus despite of $1 / 3$ scale, full amplitude is considered. In addition to the forced vibration test, free vibration test and microtremor measurement were performed for each case. The damage in each case was introduced by cutting a fracture on the elements or disconnecting beam-column or base-column bolted connections. The damage pattern of column is shown in Figure 1. Experimental cases are presented in Figure 2.

The configuration cases shown in Table 1 are as follow:

Case 1: The configuration of the frame model for the first case was an undamaged structure. The undamaged steel frame was measured for microtremor measurement, free vibration and the full amplitude for forced vibration. 


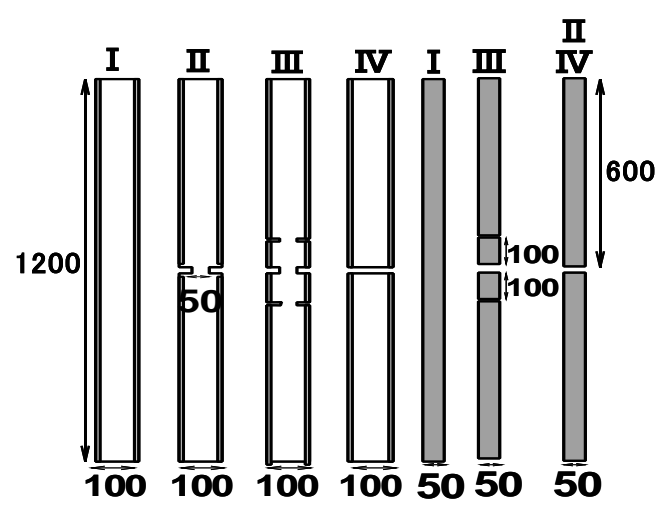

Figure 1. Damage pattern (Unit: mm).
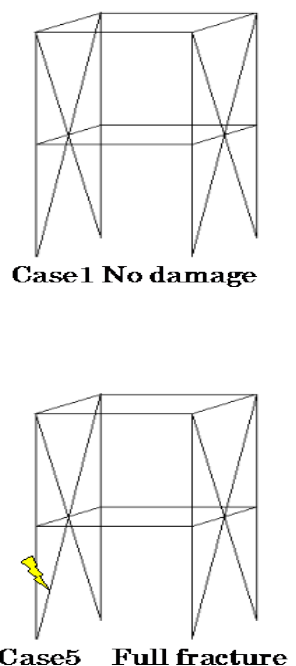

at the first floor (PatternIv)

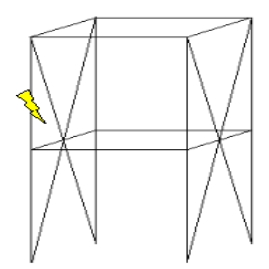

Case9 Full fracture at the second floor (PatternIV)

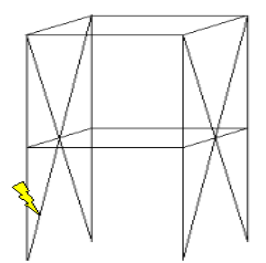

Case2 Partial fracture at the first floor (Pattern II)

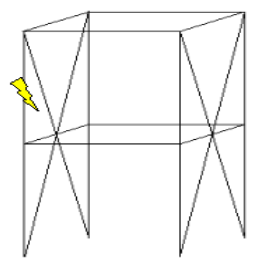

Case6 Partial fracture at the second floor (Pattern II)

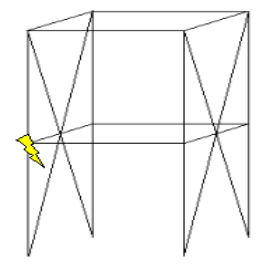

Case 10 Disconnecting at the first floor

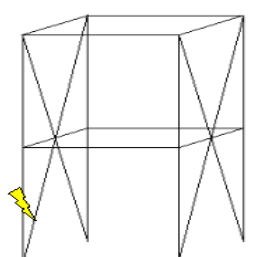

Case3 Partial fracture at the first floor (PatternIII)

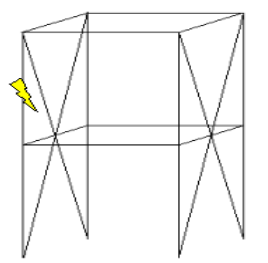

Case7 Partial fracture at the second floor (PatternIII)

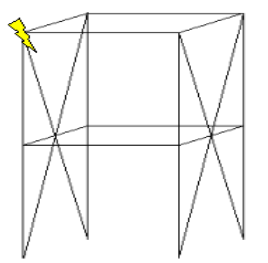

Case11 Disconnecting at the second floor

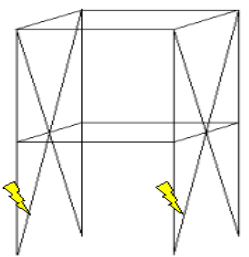

Case4 Partial fracture at the first floor (Pattern II ) $\times 2$

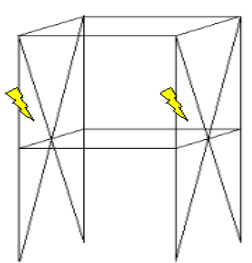

Case8 Partial fracture at the second floor (Pattern II) $\times 2$

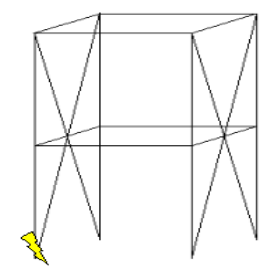

Case12 Disconnecting at found ation

\section{Figure 2. Damage cases.}

Case 2: The damage was introduced to the frame by cutting a fracture on the middle of the profile up to $50 \%$ width of the both sides. The damaged column was considered at the first floor and as shown in Figure 2, indicated with number 2 of the damage pattern.

Case 3: The damage level in this case was larger than Case 2. In this case damage was introduced to the frame by cutting three fractures on the middle of the profile up to $1 / 3$ width of the both sides in the first floor.

Case 4: The damage was introduced to the frame by same as Case 2. But two damaged columns were considered at the first floor.

Case 5: The damage was introduced to the frame by a complete cut at the middle of the column. The damaged column was attached to the first floor such as Case 2. 
Table 1. Configuration of damage cases.

\begin{tabular}{ccc}
\hline No. & Damage case & Damage pattern of column \\
\hline 1 & No damage & 2 \\
2 & Small partial fracture at the first floor & 3 \\
3 & Large partial fracture at the first floor & $2 \times 2$ \\
5 & Small partial fracture at the first floor $\times 2$ & 4 \\
6 & Full fracture at the first floor & 2 \\
7 & Small partial fracture at the second floor & 3 \\
8 & Large partial fracture at the second floor & $2 \times 2$ \\
10 & Small partial fracture at the second floor $\times 2$ & 4 \\
11 & Full fracture at the second floor & - \\
12 & Disconnecting at the first floor & - \\
\hline
\end{tabular}

Cases 6-9: The damage was as same as Cases 2-5 but in the second floor.

Case 10: In this case damage condition was introduced to the frame by disconnecting the beam-column connection in the first floor. The disconnected connection is indicated with the sign in Figure 2.

Cases 11: The damage was similar to Case 10 but the locations were in the second floor.

Case 12: In this case damage condition was introduced to the frame by disconnecting the base-column connection at the foundation.

\section{Experimental Studies}

In this study three kinds of measurements were performed: Microtremor measurement, free vibration test and vibration test by using the shaking machine. These three methods are described as follows.

\subsection{Microtremor Measurements}

One of the disadvantages of the shaking table measurements is the scale of structures which means that we cannot put desired structures on the shaking table, thus microtremor would be a handy method in order to measure dominant waves and amplifications. Microtremor measurement was performed by using six Microtremor-meters. The meters were set up in 2 directions on the beam of the second floor, first floor and the base level. Figure 1 shows a typical meter layout of the locations and directions on each floor level.

\subsection{Free Vibration and Vibration Test}

Free vibration test was performed to evaluate dynamic properties of the model structures. Free vibration was made by applying and then sudden releasing of a static force on the beam of the roof level by the manpower [11]-[13]. Figure 3 also shows locations layout of accelerometers and directions of accelerometers.

Shaking machine was installed at the roof, on top of a steel plate. Weight of the machine used in vibration test was about 200N. The shaking level was maximum magnitude of the shaker force. Applied load at roof level was approximately $900 \mathrm{~N}$. Measurements were taken in three locations on each floor. Measurements for two directions were taken in one location at the base level.

\subsection{Natural Frequency}

The natural frequency in the lateral direction was estimated using the microtremor measurements and vibration tests [14]. The data was analyzed in the frequency domain by using FFT analyses [14]-[17]. The results of natural frequency for all damage cases in the free vibration test and microtremor measurement are shown in Figure 4. This figure shows the natural frequencies of undamaged and damaged steel frame. The natural frequencies of 


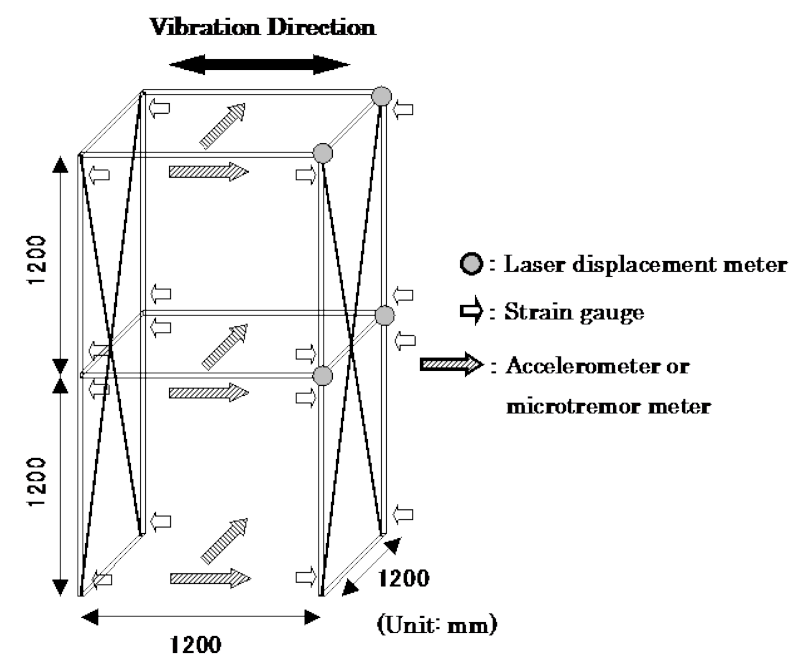

Figure 3. Experimental model.

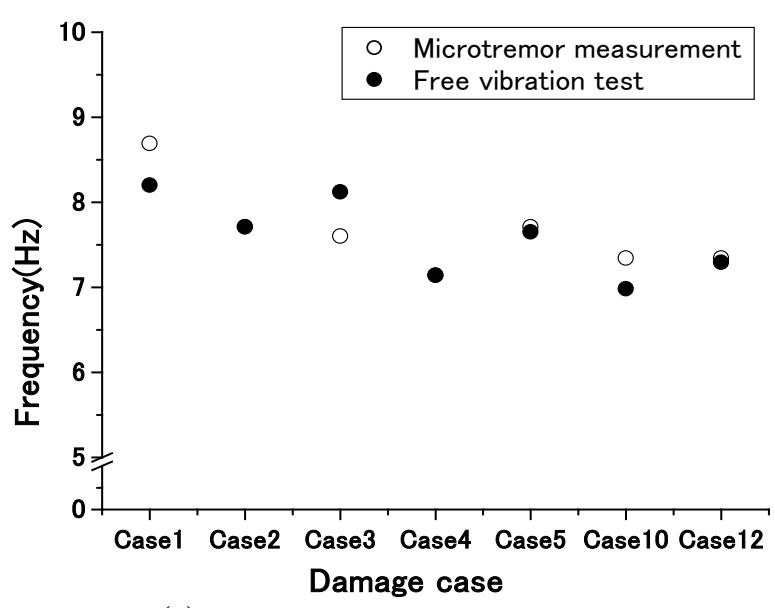

(a) Damage cases at the first floor.

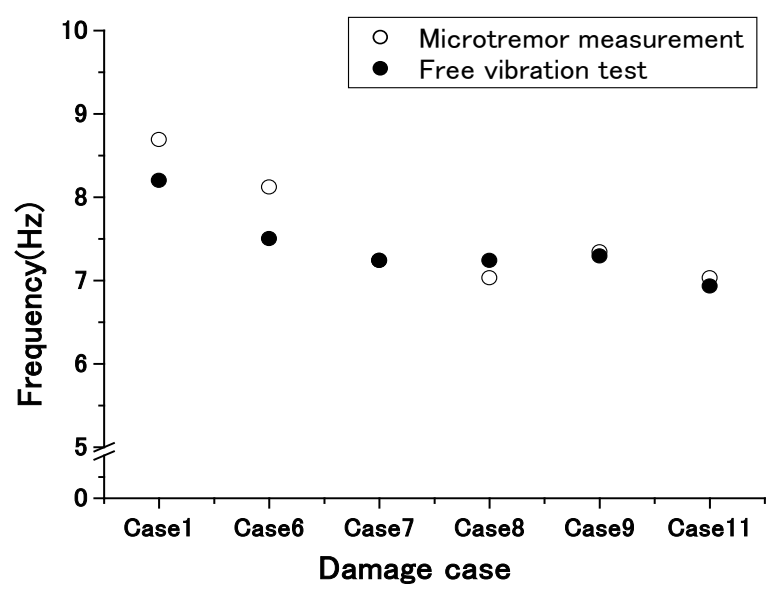

(b) Damage case at the second floor.

Figure 4. Relationships between damage cases and natural frequency.

microtremor measurements of the structure are same as those obtained by the free vibration test. This figure was categorized by the results at the first floor and the second floor. The values of natural frequencies of damage cases decrease in comparing with undamaged one. As mentioned above, it is possible to have an estimation of the sensitivity in the model and member properties. As a result we can say that, damage evaluation of the whole model from natural frequency is possible. However, it is obvious that damage evaluation of model in details is difficult.

In the next step, we estimate the floor position of the damaged structure. Amplitude of microtremor wave is a few microns and the signal of the laser sensor is very small. Therefore, we measured displacement at each floor level by using vibration tests.

The ratio of relative displacement in the first and second floors was defined as the index to detect the damaged floor. Figure 5 shows the comparison between these values with damage cases. As we can see in case of the first floor, the ratios become low according to the fracture scale of the frame (Cases 2, 5, 10). In the second floor same as the first floor, the ratio also increases according to the fracture scale of the frame (Cases 6, 9). However, in the damage cases by disconnecting the beam-column connection in the second floor in Case 11 and the base-column connection in Case 12, we cannot find damage detection by using this presented ratio because, it is difficult to evaluate the change of dynamic behavior by disconnecting the connection.

In order to detect the damage, the ratio was calculated. In the third step, the maximum strain ratio of damaged 
frame to undamaged frame was used to detect the member of damaged frame. The relationship between the ratios and damage cases in the forced vibration tests was shown in Figure 6. The tendency in the results has a characteristic in which strain of the column with damage becomes small. The location and number of the strain gauges and the calculation method of the strain ratio were shown in Figure 7. The difference of the maximum strain ratio in two columns become large as damage grade becomes larger. The maximum strain ratio of the undamaged frames is close to 1 . The similar trend also was appeared at the second floor. In the disconnection cases, the ratio of No. 8/6 located at the base level becomes low, if the damage occurs at another member of the frame. Therefore, this method was used as benchmark for comparison the damaged model to detect the damage.

A method has been conducted in the area of damage evaluation based on changes in dynamic properties of the structure. This method can be classified into three levels according to their performance.

Level I: The method that just identifies damage if it occurs.

Level II: The method that identifies damage if it occurs and determine the floor of the damage.

Level III: The method that identifies damage if it occurs and determines the location and estimates severity of the damage.

To detect the damage which was created to the frame, the presented method was applied to model structure. A non-destructive damage evaluation technique was performed in this study by using the results from the forced vibration test.

\section{Conclusion}

As mentioned above, by using three steps of the health monitoring techniques, changes in the natural frequency and maximum strain ratio showed that the damage evaluation of structure models was possible. As a future subject, this technique will be applied to an actual structure. Also more damage patterns like bending and buckling cases should be considered.

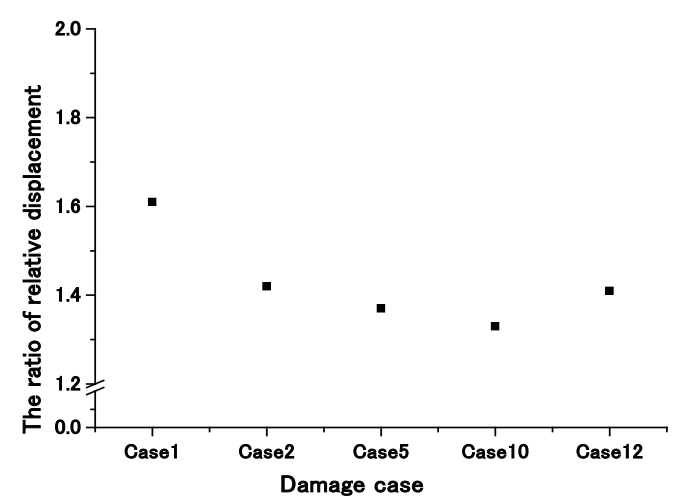

(a) Damage case at the first floor.

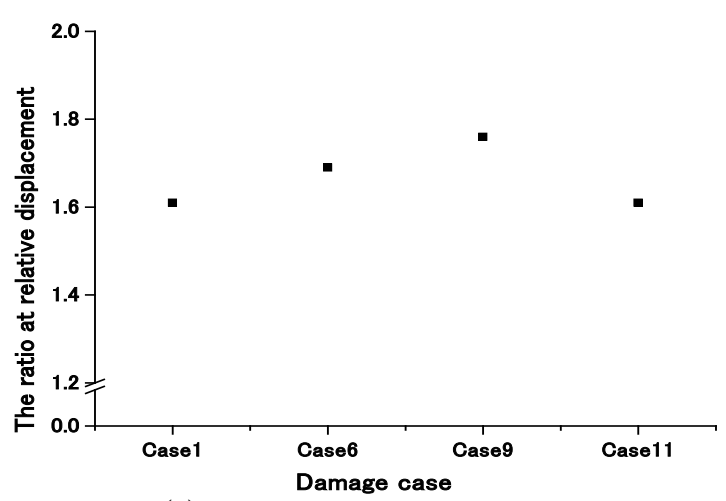

(b) Damage case at the second floor.

Figure 5. Relationships between damage cases and the ratio of relative displacement.
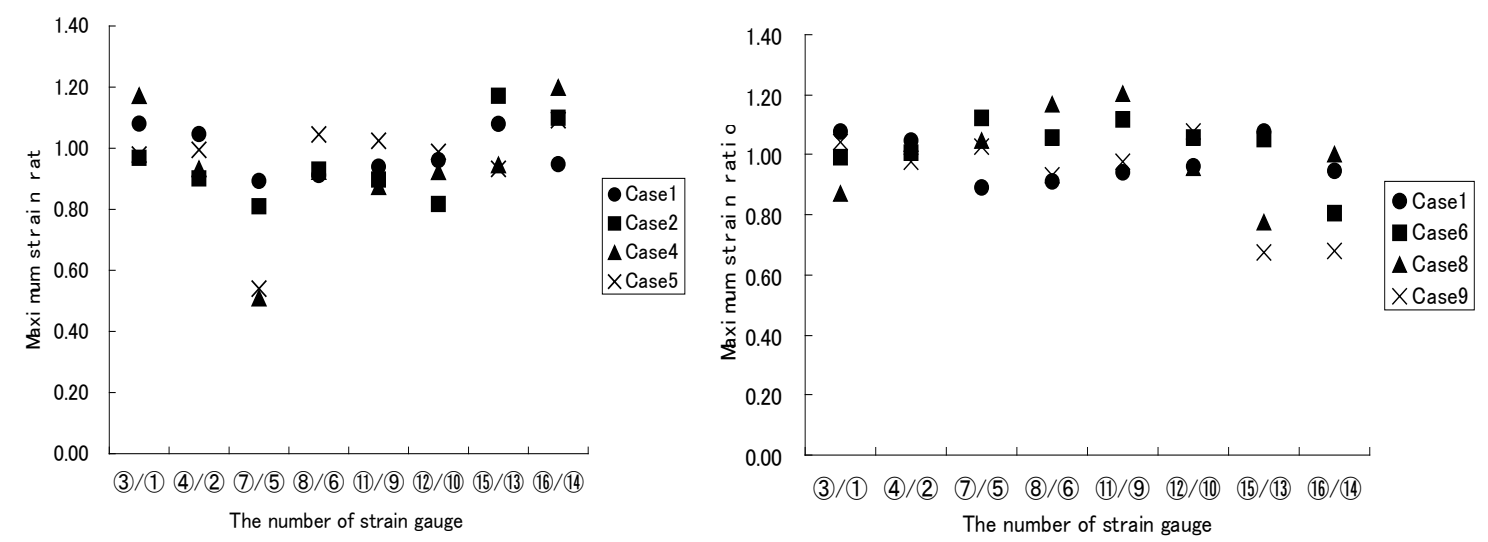

Figure 6. Relationships between damage cases and maximum strain ratio. 


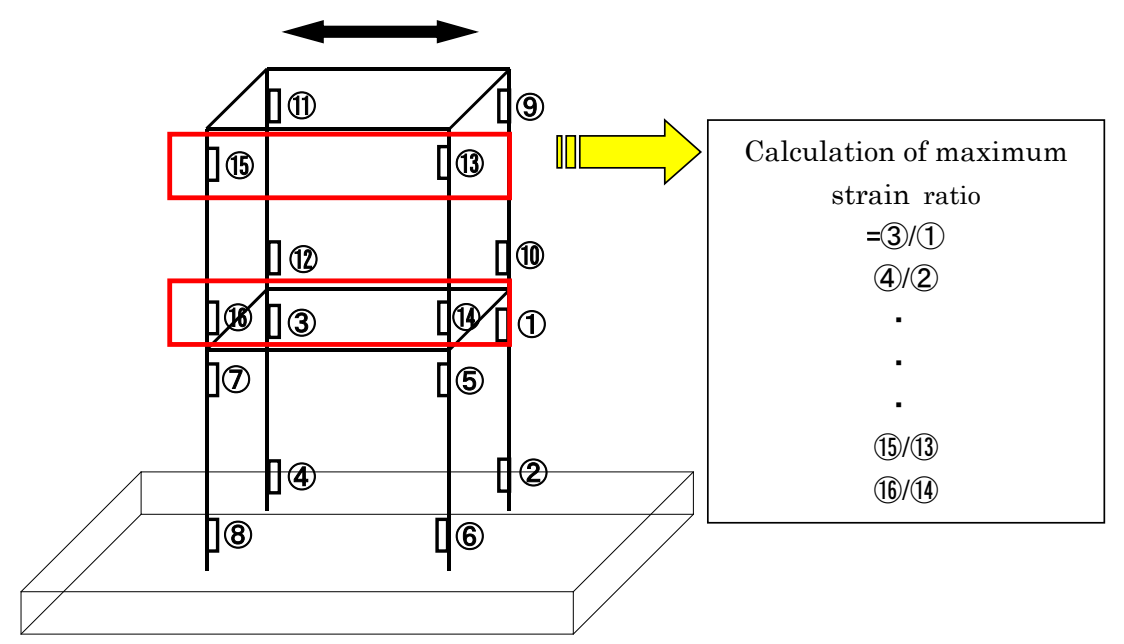

Figure 7. Location of strain guage.

\section{Acknowledgements}

The measurements were conducted with the assistance of participating students of Kanazawa University. A part of the expense of the study was supported by a Grant-in-Aid for research from the Ministry of Education, Science and Culture of Japan.

\section{References}

[1] Loh, C.H. and Tou, I.C. (1995) A System Identification Approach to the Detection of Changes in Both Linear and Non-Linear Structural Parameters. Journal of Earthquake Engineering and Structural Dynamics, 24, 85-97. http://dx.doi.org/10.1002/eqe.4290240107

[2] Sone, A., et al. (1995) Estimation of Cumulative Damage of Building with Hysteretic Restoring Force by Using Wavelet Analysis of Strong Response Records. Journal of Structural and Construction Engineering, AIJ, No. 476, 67-74.

[3] Kitagawa, Y., et al. (2003) The Study on Diagnostic System of Structural Damage and Degradation. Journal of Structural Engineering, 49B, 57-62.

[4] Sutoh, A. and Hoshiya, M. (1996) Optimization of Steel Structural System under Earthquake Excitation. Proceeding of 11th World Conference on Earthquake Engineering. CD-ROM.

[5] Ventura, C.E., et al. A Study on Damage Detection Using Output-Only Modal Data. http://vbn.aau.dk/files/12774317/A_Study_on_Damage_Detection_Using_Ouput-Only_Modal_Data

[6] Salawu, O. (1997) Detection of Structural Damage through Changes in Frequency: A Review. Engineering Structures, 19, 718-723. http://dx.doi.org/10.1016/S0141-0296(96)00149-6

[7] Lifshitz, J. and Rotem, A. (1969) Determination of Reinforcement Unbonding of Composites by a Vibration Technique. Journal of Composite Materials, 3, 412-423. http://dx.doi.org/10.1177/002199836900300305

[8] Hearn, G. and Testa, R. (1991) Modal Analysis for Damage Detection in Structures. Journal of Structural Engineering, 117, 3042-3062. http://dx.doi.org/10.1061/(ASCE)0733-9445(1991)117:10(3042)

[9] Hasan, W. (1995) Crack Detection from the Variation of the Eigenfrequencies of Abeam on Elastic Foundation. Engineering Fracture Mechanics, 52, 409-421. http://dx.doi.org/10.1016/0013-7944(95)00037-V

[10] Sinou, J.-J. (2007) Numerical Investigations of a Robust Identification of Crack Location and Size in Beams Using Only Changes in Ratio Pulsations of the Cracked Beams. Structural Engineering Mechanics, 25, 691-716.

[11] Caron, J.N., DiComo, G.P. and Nikitin, S. (2011) Generation of Ultransound in Materials Using High Power Fiber Lasers. Optics Letters, 37830-37832.

[12] Staszewski, W.J., Lee, B.C. and Traynor, R. (2007) Fatigue Crack Detection in Metallic Structures with Lamb Waves and 3D Laser Vibrometry. Measurement Science and Technology, 18, 727-739. http://dx.doi.org/10.1088/0957-0233/18/3/024

[13] An, Y.-K. and Sohn, H. (2011) Instantaneo Crack Detection under Varying Temperature and Static Loading Conditions. Structural Control \& Health Monitoring, 17, 730-741. http://dx.doi.org/10.1002/stc.394 
[14] Ruzzene, M. (2007) Frequency-Wavenumber Domain Filtering for Improved Damage Visualization. IOP Publishing, Smart Material and Structures, 16, 2116-2129. http://dx.doi.org/10.1088/0964-1726/16/6/014

[15] Giurgiutiu, V. (2005) Tuned Lamb Wave Excitation and Detection with Piezoelectric Wafer Active Sensor of Structural Health Monitoring. Journal of Intelligent Material Systems and Structures, 16, 291-305. http://dx.doi.org/10.1177/1045389X05050106

[16] An, Y.-K., Park, B. and Sohn, H. (2013) Complete Noncontact Laser Ultrasonic Imaging for Automated Crack Visualization in a Plate. Smart Material and Structures, 22, 1-10. http://dx.doi.org/10.1088/0964-1726/22/2/025022

[17] Raghavan, A. and Cesnik, C.E.S. (2007) Review of Guided-Wave Structural Health Monitoring. Shock \& Vibration Digest, 39, 91-114. http://dx.doi.org/10.1177/0583102406075428 
Scientific Research Publishing (SCIRP) is one of the largest Open Access journal publishers. It is currently publishing more than 200 open access, online, peer-reviewed journals covering a wide range of academic disciplines. SCIRP serves the worldwide academic communities and contributes to the progress and application of science with its publication.

Other selected journals from SCIRP are listed as below. Submit your manuscript to us via either submit@scirp.org or Online Submission Portal.
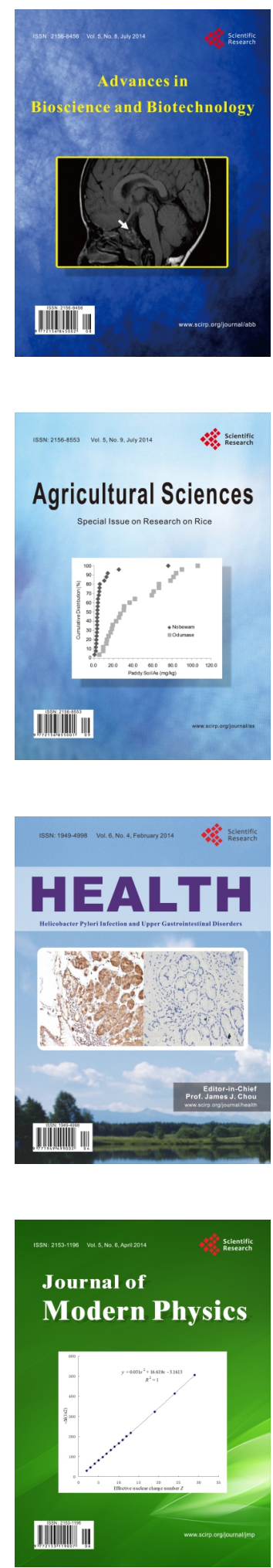
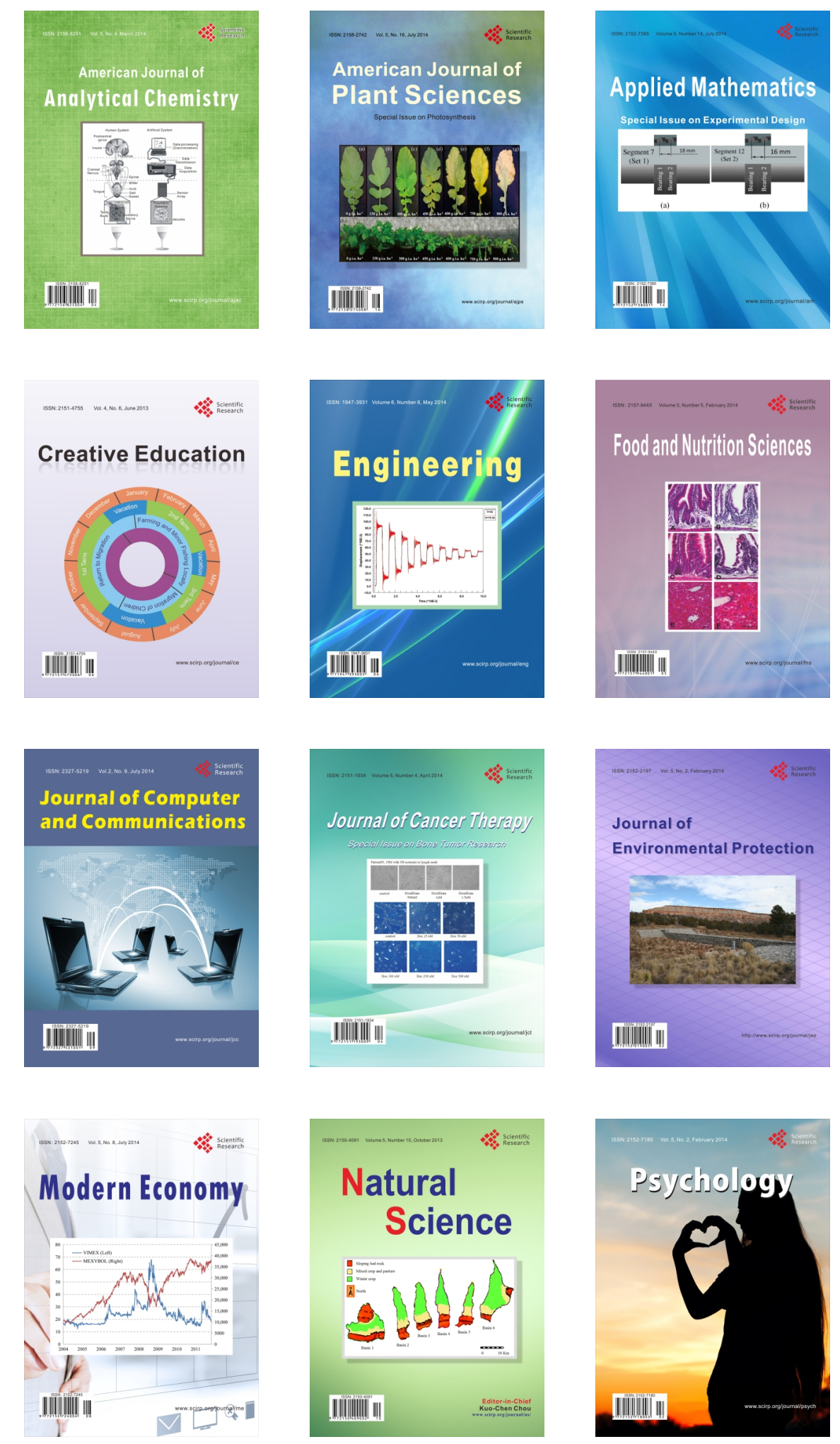